\title{
Vaccine Cold Chain Monitoring System Using loT Vaccine Fridge for Developing Countries
}

\author{
Jang-Hyeon Lyu', Samuel Park ${ }^{1}$, Jong-Ha Yu ${ }^{1}$, Xin-Lin Wang ${ }^{1}$, \\ Hyuck-Soon $\mathrm{Im}^{3}$, Hyop-Seung Rhee ${ }^{3}$, Sung-Hoon Ahn ${ }^{1,2, \uparrow}$ \\ ${ }^{1}$ Department of Mechanical Engineering, Seoul National University, Seoul, Republic of Korea \\ ${ }^{2}$ Institute of Advanced Machines and Design, Seoul National University, Seoul, Republic of Korea \\ ${ }^{3}$ Innovative Technology and Energy Center (iTEC) - Tanzania, Arusha, Tanzania
}

\section{IoT 백신 냉장고를 사용한 개발도상국 백신 콜드체인 모니터링 시스템}

\author{
유장현 ${ }^{1}$, 박사무엘 ${ }^{1}$, 류종하 ${ }^{1}$, 왕심린 $^{1}$, 임혁순 $^{3}$, 이협승 ${ }^{3}$, 안성훈 $^{1,2, \uparrow}$ \\ ${ }^{1}$ 서울대학교 기계공학부 \\ ${ }^{2}$ 서울대학교 정밀기계설계공동연구소 \\ ${ }^{3}$ Innovative Technology and Energy Center(iTEC)
}

\begin{abstract}
콜드체인의 마지막 단계인 백신전달 과정에서 대부분 얼음을 넣은 단열컨테이너로 온도를 조절하며, 백신의 온도 조 절이 적절하지 않아 낭비되는 백신의 양이 상당하다. 예방접종을 관리하고 운영하는데 온도 데이터가 중요하며, 본 연 구에서는 실시간 백신전달 모니터링 시스템을 개발하였다. 휴대용 백신 냉장고의 온도, 위치 및 전력 소비 데이터를 수 집하기 위해 문자(Short Message Service) 통신 방법을 사용하였고, 한국과 탄자니아(아루샤 및 킬리만자로 지역)에서 시스템을 테스트하였다. 개발된 백신 냉장고는 문자통신을 통해 데이터 손실없이 실시간으로 백신상태를 모니터링을 할 수 있었다. 백신의 상태 및 데이터는 클라우드 서버를 통해 웹 기반 유저 인터페이스에서 확인할 수 있었다.

In the process of vaccine delivery and vaccination, temperature is mostly controlled by an insulated containers containing ice. Moreover, amount of wasted vaccine is significant because the temperature of the vaccine is not properly controlled. A core challenge of vaccination is temperature data monitoring, since it is critical for managing and operating strategical vaccination by health organizations. In this research, a real-time monitoring vaccine carrier system was developed. Temperature, location, and power consumption data of the vaccine carrier were monitored and working performances of the vaccine carrier were tested in both Korea and Tanzania (Arusha and Kilimanjaro regions). For both places, Short Message Service (SMS) communication method was used to send information of the carrier's status. As a result, the monitoring system was able to transmit and receive real-time data of the vaccine carrier status while the vaccine carrier was tested. The vaccine status data can be accessed from any location through the cloud server and web-based user interface.
\end{abstract}

KEYWORDS: Real-time monitoring system, Rural village, SMS communication method, Vaccine fridge, Vaccination

\section{Introduction}

예방접종은 전염병을 예방하고 질병, 장애 및 사망을 막

\footnotetext{
†To whom correspondence should be addressed.

E-mail: ahnsh@snu.ac.kr

Received: 17 September 2020, Revised : 20 April 2021,

Accepted: 10 May 2021
}

을 수 있는 가장 비용 효율이 높은 방법 중 하나이다. 백신 은 감염성 질병에 대한 보호를 하고, 적절히 사용하면 질병 을 박멸시킬 수 있다. 백신은 예상수명을 늘려 사회 복지를 높일 수 있는 잠재력 또한 가지고 있다. 그러나, 백신의 온 도에 대한 매우 민감한 특성으로 인해 백신의 지속적인 공 급에 비해 전 세계적으로 많은 사람들이 예방접종을 받지 못하고 있다. 세계보건기구(World Health Organization, 
$\mathrm{WHO})$ 에 따르면, 정기 예방접종을 받지 못하는 영아는 2019 년 기준 1,970 만명의 영아 중 1,400 만명이 넘을 것으로 예 측한다. 또한, 개발도상국을 포함한 세계 많은 나라에서의 예방접종기록은 수기로 작성되어 집에 보관되기에 누가 백 신을 필요로 하고, 누가 접종을 했는지 명확하게 파악하기 어려움이 있다(Kartoglu and Milstien, 2014; WHO, 2020b). 코로나바이러스감염증-19(COVID-19), 사스(SARS), 메르 스(MERS)와 같이 신종 유행 감영병은 발병후에 빠른 속도 로 전염되기에 백신이 개발된 후에 빠른 속도로 접종을 진 행해야 된다. 하지만, 백신은 바이러스나 단백질 등 생체물 질을 이용하기 때문에 온도에 매우 민감하며, 대부분의 백 신은 낮은 온도를 유지해야한다(Michelle and Gregory, 2021). 백신마다 온도에 따른 민감도가 달라 폐기율이 다르지만, 대 부분의 백신은 최소 $15 \%$ 에서 최대 $50 \%$ 가 유통과정의 온도 조절 미흡으로 폐기되고 있다(Aaron et al., 2017; Stephane et al., 2010). 에너지, 환경, 보건 등의 개선으로 개발도상국 에서 신산업국(Newly Industrialized Country)이 된 인도의 일부 지역에서도 코로나바이러스감영증-19 백신의 폐기율 이 $17.6 \%$ 에 달한다(The Indian Express, 2021). 전세계적으 로 급격히 유행하는 질병으로 공급난을 겪고 있는데, 폐기 되는 백신으로 인해 다른 개발도상국까지 예방접종하기 까 지는 많은 시간이 걸릴 것으로 예측되며, 백신의 유통과정 이 더욱 중요시 되고 있다.

개발도상국에서 낮은 예방접종율의 다른 원인에는 빈곤, 자원에 대한 제한된 접근성, 불리한 운송 인프라가 있다. 낮 은 예방접종율 문제는 하루아침에 해결될 간단한 문제가 아 니며, 그 이유는 전세계 콜드 체인 시스템(Cold chain system) 에 있다(Ashok et al., 2017; Cheriyan, 1993; Hanson et al., 2017; Kumru et al., 2014; Nelzon et al., 2007). 예방접종과 콜드체인 시스템의 핵심 과제는 데이터 모니터링이며 그 이 유는 전략전인 예방접종 시스템을 가능하게 하여 예방접종 율을 높일 수 있기 때문이다. 위치정보가 포함된 예방접종 데이터는 지역별 예방접종계획을 관리하기 편할 것이다. 기 록된 데이터는 세계보건기구(WHO)와 같은 국제 기관이 예 방접종 서비스를 효율적으로 관리하고 모든 영유아와 임산 부가 예방접종을 받도록 함으로써 예방접종 프로그램의 질 을 향상시키는 데 도움이 될 수 있다. 이는 국가적차원에서 필수로 예방접종이 진행되는 결핵(BCG), $\mathrm{A}$ 형\&B형 감염 $(\mathrm{HepA}, \mathrm{HepB})$ 과 같은 기존 질병에 대한 예방접종 뿐만 아 니라 신종 유행 감염병에 대한 예방접종계획 관리에 많은 도움이 될 것이다. 또한 많은 백신은 열에 대한 노출, 동결 , 파손, 재고 누락 및 도난으로 인해 낭비하게 된다. 백신의 효율을 유지하기 위해서는 백신을 보급하는 전 과정에서 백 신이 적정 온도를 유지해야한다 $\left(2 \sim 8^{\circ} \mathrm{C}\right)$. 백신 모니터링이
올바르게 수행되면 이러한 문제가 해결되고 백신의 낭비를 줄일 수 있다.

IoT(Internet of Things, 사물인터넷)을 기반 통신기술의 발 전과 4차 산업혁명의 도래는 예방접종에서의 문제점들에 대 한 해결책으로 보인다(Setia et al., 2002). IoT를 통해 세계 어디서든 백신의 온도 및 상태를 지속적으로 모니터링하고 확인할 수 있게 되었다. 예방접종 데이터는 집 기반 수기 작 성 시스템에서 인터넷 기록 시스템으로 변경되어 예방접종 일정 관리하기가 더 정확하고 체계적으로 이루어 질 수 있 다. IoT를 활용하여 많은 선진국들의 질병관리본부(Centers for Disease Control and Prevention, $\mathrm{CDC}$ )는 인구 기반의 컴 퓨터화 된 데이터베이스를 사용하여 모든 사람들의 예방 접 종 기록을 관리하는 예방접종 정보 시스템(Immunization Information System, IIS)을 구축했다.

탄자니아, 네팔 등을 포함한 개발도상국들의 특징 중 하 나는, 도시지역과 오지지역의 에너지 공급망의 차이가 크다 는 것이다(Ahn et al., 2012; Bhandari et al., 2014a, 2014b, 2015; Kim et al., 2020; Wang et al., 2020a, 2020b; Energy Information Administration, 2016). 개발도상국에서는 계속 해서 지역발전소를 구축하고 있지만 아직까지도 오지지역 에 전기 공급이 원활하지 않아 병원에서 환자까지 얼음을 넣은 단열컨테이너로 백신을 운송되고 있다(Mun, 2018).

기존 선진국의 휴대용 백신 냉장고(Vaccine carrier)의 데 이터 모니터링은 대부분 블루투스와 와이파이를 이용하여 진행되어 왔다. 이는 통신망 $(2 \mathrm{G}, 3 \mathrm{G}, 4 \mathrm{G})$ 을 사용하지 않고, 근거리 통신만 가능하며, 근접한 휴대폰과 같은 IT기기에 데 이터를 전송하고 저장하였다(Kim et al., 2020; Lloyd and Cheyne, 2017; WHO, 2020a). 이에 IT기기의 분실로 인한 데 이터 손실우려가 있으며, 온라인 클라우드 연동이 없어 제

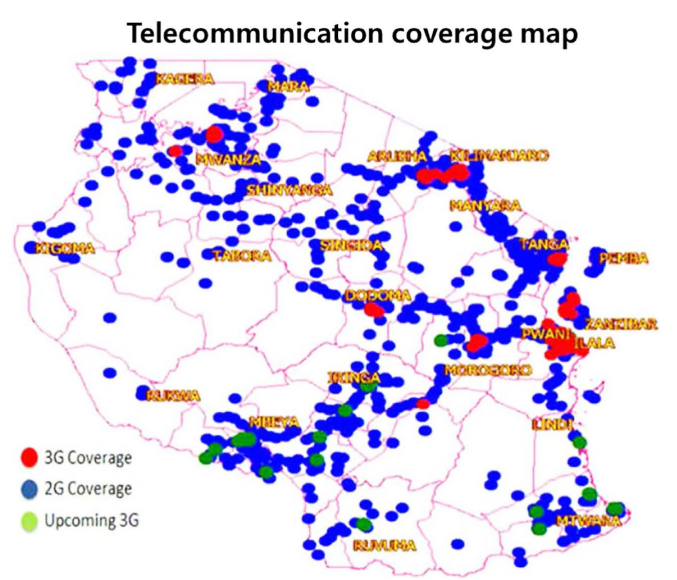

Figure 1. Halotel telecommunication service coverage map in Tanzania (TanzaniaInvest, 2016) 


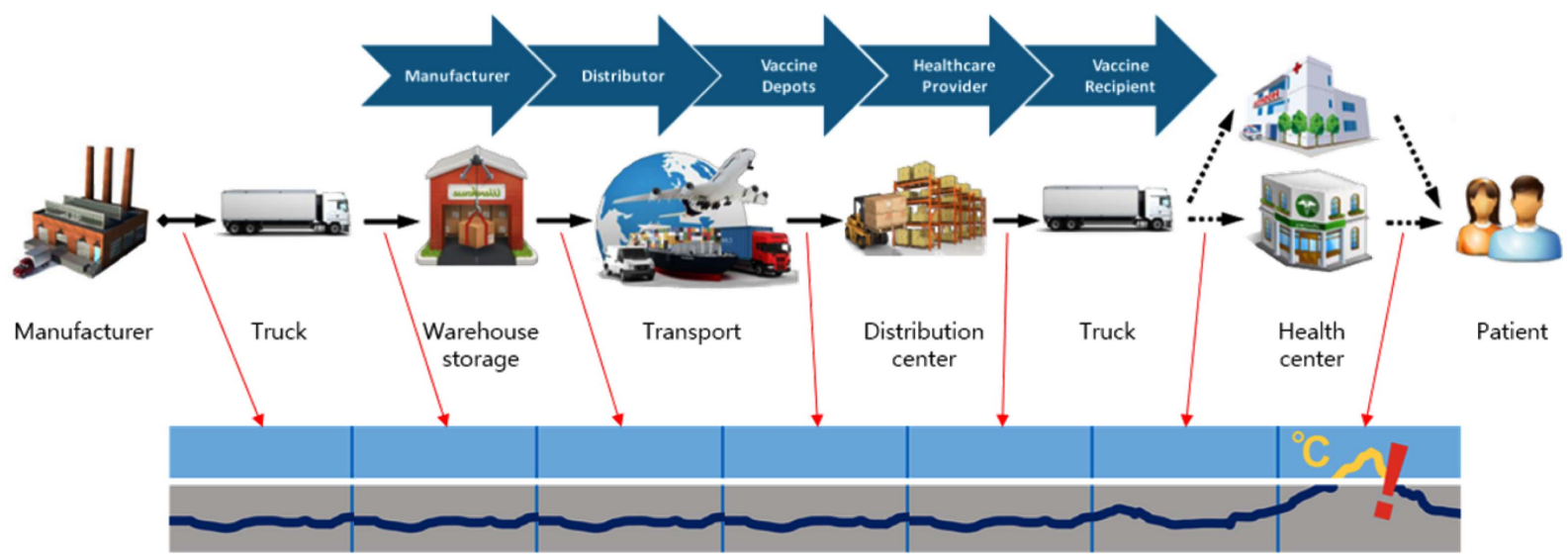

Figure 2. Vaccine delivery process

3자가 데이터를 확인하는데 어려움이 있다.

본 연구에서는 백신의 상태를 제3자가 실시간으로 확인 하기 위한 휴대용 백신 냉장고와 백신 모니터링 시스템을 제안한다. 개발도상국 외지에서도 실시간으로 모니터링하 기 위한 문자 $(2 \mathrm{G})$ 기반 모니터링 장치가 개발되었다. 통신

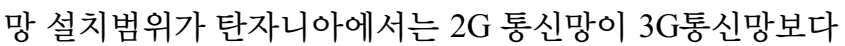
넓기 때문에(Fig. 1) 2G 통신을 사용하였다(Byanyuma et al., 2018).

본 연구는 탄자니아 에너지-산업 연계 적정기술거점센터 (Tanzania-Korea Innovative Technology and Energy Center) 프로젝트의 일부로, 연구 목적으로 탄자니아의 아루샤 (Arusha)와 킬리만자로(Kilimanjaro) 지역에서 테스트가 진 행되었다(Park, 2019).

\section{Vaccination process}

백신은 백신제조사에서 실제 사용 환자까지 전달되는 과 정에서 많은 운송 단계를 거치게 된다. 제조사에서 백신이 제작되어 창고, 물류창고, 병원으로 운송하는 과정은 대량 운송으로 운송되기에 백신 관리시스템이 체계적으로 이루 어져 있어 백신의 성능과 품질을 보장할 수 있다. 하지만 병 원에서부터 환자까지 운송하는 과정에서는 백신 모니터링 시스템이 없어 백신의 품질을 보장하기 어렵다(Fig. 2).

탄자니아 아루샤 지역에서는 각 마을의 병원 혹은 진료 소에서 실내용 백신 냉장고에 보관 후 예방접종시에 실 접 종지역으로 백신을 운송하여 예방접종을 진행한다. 접종지 역으로 운송하기 위해 휴대용 백신 냉장고에 백신을 옮긴 후 도보 혹은 차량을 이용한다. 예방접종 과정에서도 휴대 용 백신 냉장고에 백신을 보관하여 모든 과정에서 백신이 최상의 상태를 유지할 수 있도록 한다(Fig. 3).

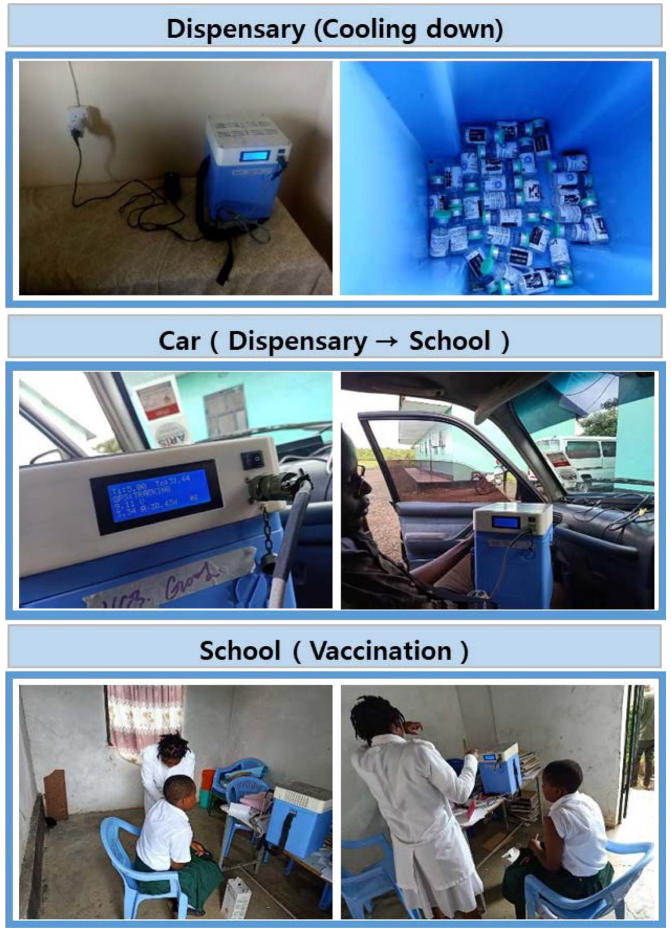

Figure 3. Nambala dispensary vaccination process in Tanzania

\section{Vaccine monitoring system design}

\section{Requirements and system design}

전반적인 모니터링 시스템은 백신 냉장고, 모니터링 장 치, 클라우드 서버의 세 부분으로 나뉜다(Fig. 4). 백신 냉 장고 모니터링 시스템은 문자통신을 데이터 통신 방법으로 사용하여 측정 데이터를 현지에 설치된 수신기로 자동 전 송하여 개발도상국의 외지에서의 통신 문제를 해결한다. 현 지의 데이터 수신기는 인터넷에 연결되어 있어 문자로 받 은 데이터를 서버에 올려 인터넷이 가능한 전 세계 모든 지 


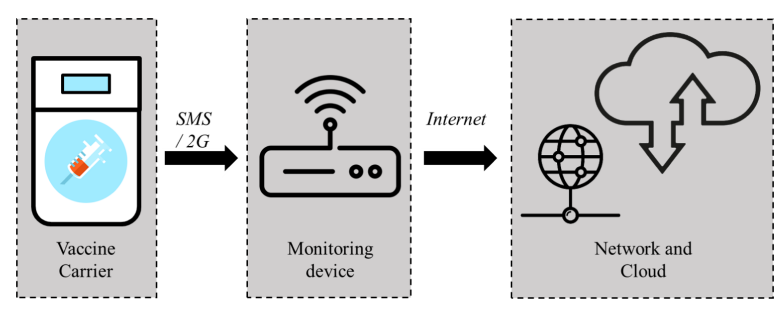

Figure 4. Overall schematic of vaccine carrier monitoring system

역에서 백신 데이터를 확인할 수 있다.

\section{Monitoring device}

백신 냉장고를 모니터링하고 추적하기 위해 모니터링 수 신기가 개발되었다. 이 장치는 인터넷, 와이파이, 블루투스 통신 없이도 데이터를 송수신 할 수 있어야 한다. 현지 모 니터링 수신기는 내부에 조립된 Arduino Mega 2560와 컴 퓨터의 직렬 통신(serial communication)을 위해 USB 포트 로 연결되며, 전원 공급을 위해 $5 \mathrm{VDC}$ 전력원에 연결된다. 문자 데이터 통신을 위해 SIM5320E 모듈이 사용되었으며, SIM5320E 모듈이 지원하는 작동 사양, 작동 네트워크 주파 수는 Table 1에 나와 있다.

Table 1. SIM5320E technical specifications

\begin{tabular}{|l|l|}
\hline Operating voltage & $5 \mathrm{~V}$ \\
\hline DC current & $>1.5 \mathrm{~A}$ \\
\hline \multirow{4}{*}{ GSM } & GSM $850 \mathrm{MHz}$ \\
\cline { 2 - 2 } & EGSM $900 \mathrm{MHz}$ \\
\cline { 2 - 2 } & DCS $1800 \mathrm{MHz}$ \\
\cline { 2 - 2 } & PCS $1900 \mathrm{MHz}$ \\
\hline \multirow{2}{*}{ WCDMA } & WCDMA $900 \mathrm{MHz}$ \\
\cline { 2 - 2 } & WCDMA $2100 \mathrm{MHz}$ \\
\hline HSPA & HSDPA \\
\hline
\end{tabular}

\section{Monitoring Application and Cloud Server}

백신 냉장고의 실시간 모니터링을 위해서는 제 3 자가 쉽 게 확인하고 사용할 수 있는 Windows 프로그램이 필요하 다. 또한, 모니터링 수신기를 통해 수신된 백신 데이터는 추 후에 사용할 수 있도록 저장해야 한다. 데이터 측정을 저장 하는 방법에는 두 가지가 있는데, 먼저 현지 컴퓨터에 로컬
파일로 저장하고 이중 저장을 위해 저장된 파일을 클라우 드 서버에 업로드하는 것이다. 프로그램은 수신된 실시간 데 이터를 시각화하고 온도 값, 경도와 위도로 표시된 위치 (GPS), 날짜, 시간 및 전력 소비와 같은 정보를 표시해야 한 다. 백신 냉장고 가 전송하는 데이터 값과 형식은 Table 2 에 나와있다.

\section{Implementation and Evaluation}

\section{Vaccine carrier hardware Design}

백신 냉장고의 전원은 $\mathrm{AC} / \mathrm{DC}$ 어댑터 또는 자동차 또는 오토바이와 같은 차량에서 공급되는 $12 \mathrm{VDC}$ 로 공급받는 다. 백신 냉장고 모니터링 장치에 포함된 온도센서, 위치센 서, 전압센서, 전류센서로부터 받은 모든 데이터는 내부에 설치된 Arduino Mega 2560의 핀을 통해 처리된다. 전압 레 귤레이터(voltage regulator)는 들어오는 $12 \mathrm{VDC}$ 를 $9 \mathrm{VDC}$ 로 변환하여 Arduino Mega 2560 및 구성 요소에 전원을 공 급하고 또 하나의 전압 레귤레이터는 $5 \mathrm{VDC}$ 를 출력하여 백 신 냉장고에 연결된 SIM5320E에 전원을 공급한다(Fig. 5).

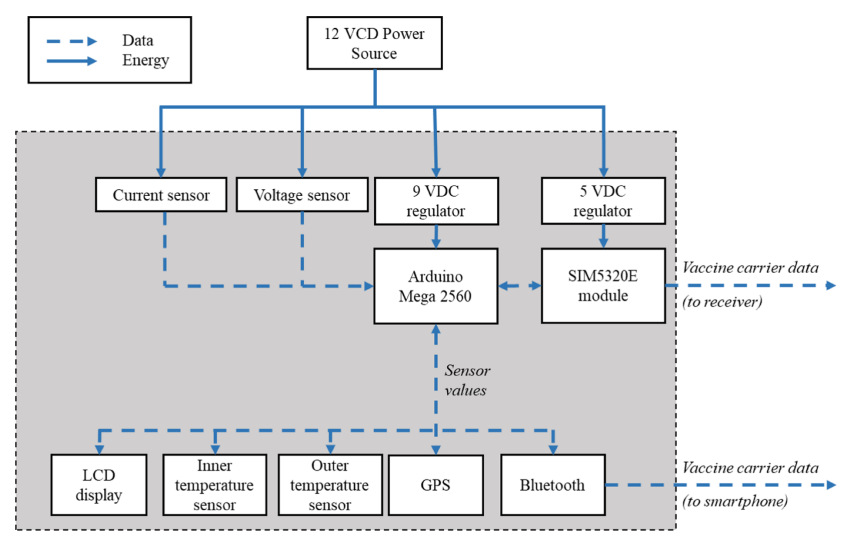

Figure 5. Detailed function diagram of vaccine carrier

\section{Software design}

Visual Studio 2017은 모니터링 프로그램을 위한 Windows Forms 앱.NET Framework)을 만드는 데 사용되었다. Windows 프로그램은 간단하고 사용자 친화적이며 직관적 인 사용자 인터페이스(UI)로 설계 및 개발되었다. 백신 냉장고 실시간 모니터링 프로그램(vaccine carrier real-time monitoring program,

Table 2. Data measurements from vaccine carrier

\begin{tabular}{|c|c|c|c|c|c|c|c|c|c|c|c|}
\hline & No. & $\begin{array}{c}\text { Outside } \\
\text { temp }\end{array}$ & $\begin{array}{c}\text { Inside } \\
\text { temp }\end{array}$ & $\begin{array}{c}\text { No. of } \\
\text { satellites }\end{array}$ & Latitude & Longitude & Date & Time & Voltage & Current & Power \\
\hline Data type & integer & float & float & integer & float & float & char & char & double & double & double \\
\hline ex) & 3 & 4.06 & 26.62 & 13 & -3.372045 & 36.854084 & $12 / 05 / 2018$ & $11: 15: 26$ & 12.03 & 6.12 & 73.61 \\
\hline
\end{tabular}




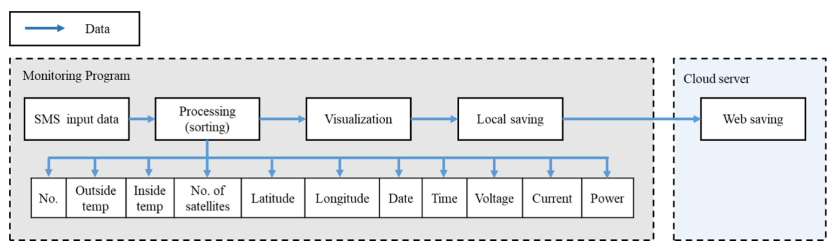

Figure 6. Detailed schematic of monitoring system

$\mathrm{VCRM}$ )과 분석 프로그램(vaccine carrier analysis program, $\mathrm{VCA})$ 의 두 가지 프로그램이 개발되었다. 백신 냉장고의 데 이터가 모니터링 수신장치를 통해 들어오면, 모니터링 수신 장치에 연결된 컴퓨터에 텍스트 및 엑셀 파일로 저장된다. 컴퓨터에 인터넷 연결이 유효하면 저장된 파일이 동기화되 어 온라인 저장공간인 Google drive에 저장된다. Google drive에 저장되고 업데이트 된 데이터는 어디서든 접근할 수 있어 사용자가 백신 및 백신 냉장고 상태 데이터를 확인하 고 평가할 수 있다(Fig. 6).

\section{Monitoring UI design}

VCRM을 통해 사용자는 실시간으로 들어오는 백신 냉장 고의 데이터를 쉽게 확인하고 백신의 상태를 평가할 수 있 도록 개발되었다. $\mathrm{VCA}$ 는 사용자가 시각적 분석 및 평가를 위해 선택한 날짜에 따라 데이터를 필터링 할 수 있도록 개 발되었다. $\mathrm{VCA}$ 는 필터링 된 데이터의 위치데이터는 프로

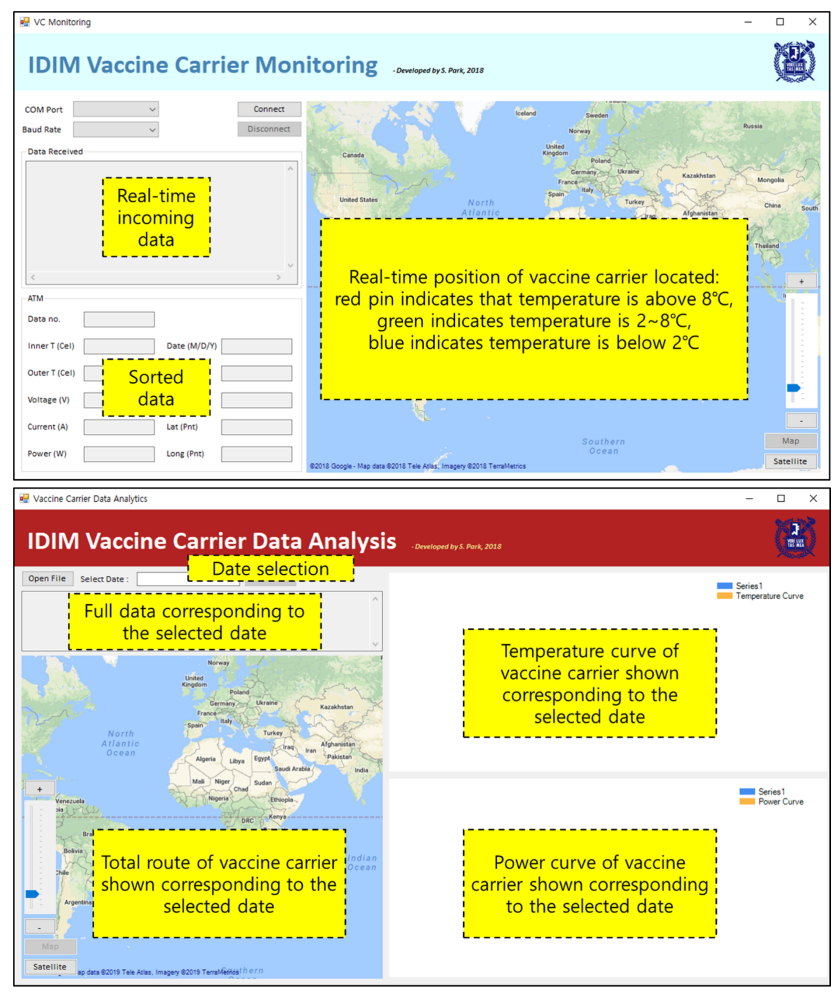

Figure 7. User interface of VCRM (top) and VCA (bottom)
그램 좌측 지도에, 온도 및 소비전력 데이터 그래프는 프로 그램 우측에 표기되도록 디자인되었다.

\section{Field test in Tanzania}

탄자니아에서 현장 테스트 및 성능 평가를 진행하기 위 해 두개의 백신 냉장고 프로토타입이 제작되었다. 두 가지 의 개별 테스트를 수행하였으며, 한 번은 오토바이를 사용

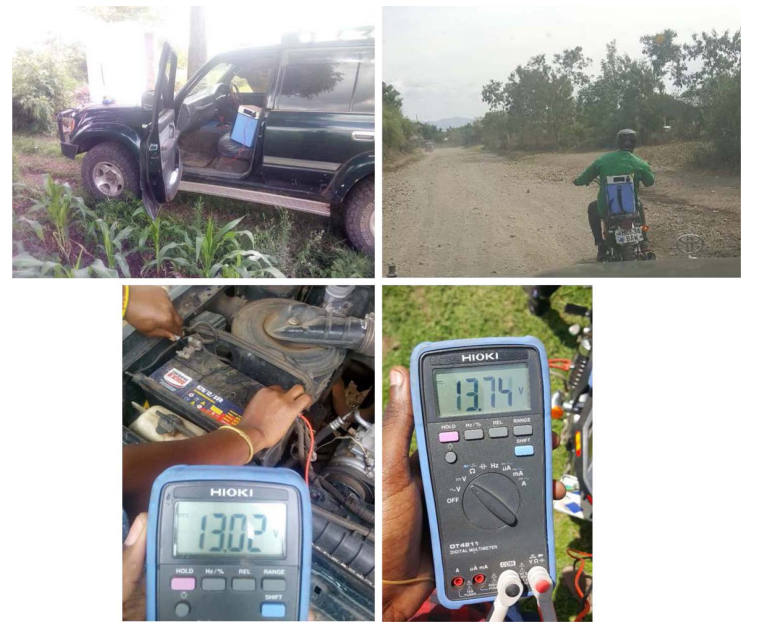

Figure 8. Vaccine carrier field test in Tanzania using a 4WD SUV (top left) and a motorcycle (top right) and checking the battery charge accordingly

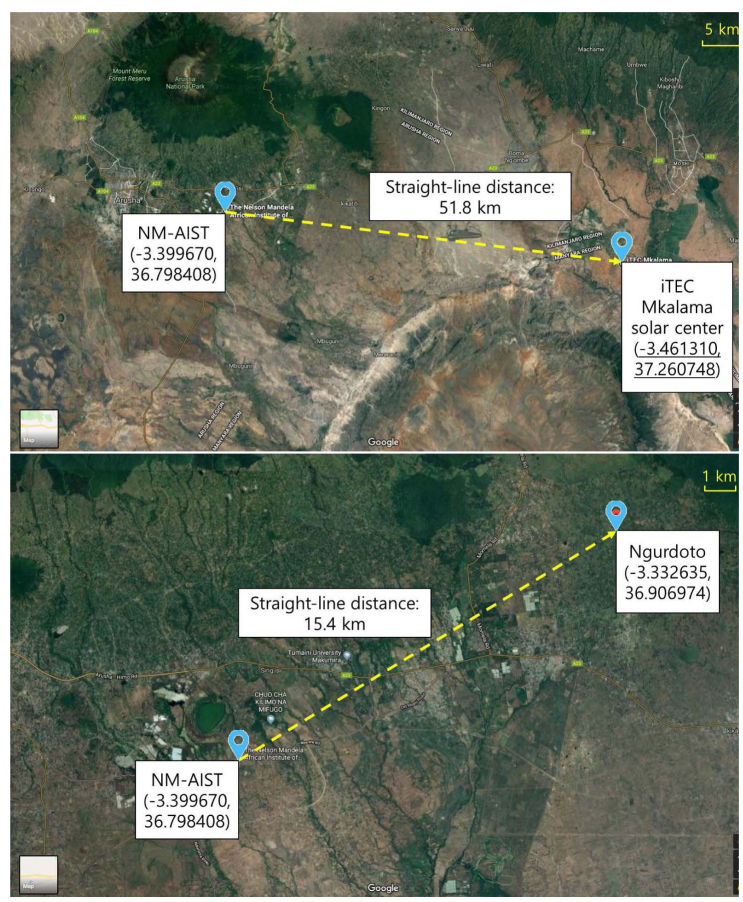

Figure 9. Locations of NM-AIST to iTEC Mkalama solar center (top) and NM-AIST to Ngurdoto village (bottom) 
하여 이송하고, 한 번은 4륜 구동(4WD) SUV를 사용하여 이 송하였다. 오토바이의 운송 테스트 경로는 Nelson Mandela African Institution of Science and Technology (NM-AIST)에 서 Mkalama 마을의 iTEC Mkalama 태양광발전센터까지 이 동 후 다시 NM-AIST로 돌아오는 직선거리 $103.6 \mathrm{~km}$ 가 사 용되었다. SUV 운송 테스트의 경우 테스트 경로는 NMAIST에서 Ngurdoto 마을까지 이동 후 다시 NM-AIST로 돌 아오는 직선거리 $30.8 \mathrm{~km}$ 가 사용되었다(Fig. 9). 차량과 오 토바이 배터리를 이용하여 백신 냉장고를 냉각시키기 위해 평균 소비전력 $60 \mathrm{~W}$ 의 냉각시스템을 같이 작동하였다. 탄 자니아의 차량 유지 관리가 불량하기 때문에 안전을 위해 멀티 미터 장치를 사용하여 테스트 경로의 각각의 체크 포 인트에서 배터리 상태를 지속적으로 테스트하였다(Fig. 8).

\section{Results and Discussion}

$\mathrm{SUV}$ 차량으로 운송 했을 때에는 안정적으로 전원이 공 급이 되고 있음을 확인했으며, 오토바이를 이용하여 운송 했 을 때에는 비포장도로의 충격으로 인해 시가 연결선과(cigar plug) 전원 공급 케이블 사이 불안정함을 확인했다. SUV 차 량 배터리와 오토바이 배터리 모두 백신 냉장고의 전원을 안정적으로 공급함을 확인했다. SUV차량의 테스트 전후 배 터리의 전압 측정 값은 각각 $13.18 \mathrm{~V}$ 와 $13.02 \mathrm{~V}$ 였으며, 오 토바이의 경우 각각 $13.74 \mathrm{~V}$ 와 $13.4 \mathrm{~V}$ 였다. 그러나 백신 냉 장고가 연결되어 작동중인 상태에서 오토바이를 정지하면 수 분 내에 측정된 전압이 $7.76 \mathrm{~V}$ 로 떨어짐을 확인했다. 교 류 발전기의 출력이 엔진 $\mathrm{rpm}$ 과 속도에 따라 달라지기 때

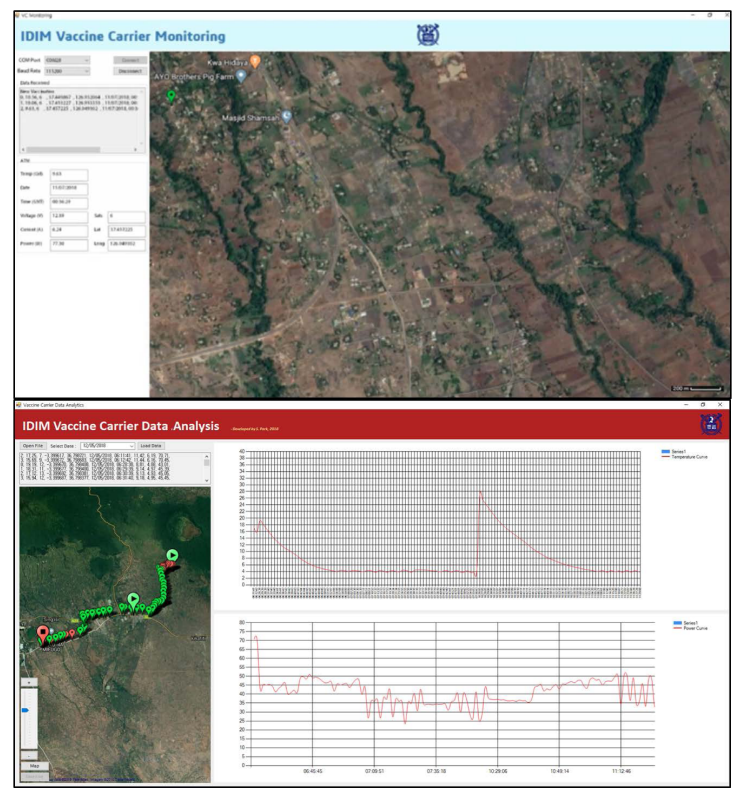

Figure 10. Result screen of VCRM (top) and VCA (bottom)
문에 주행 중 소비 데이터 측정 값은 계속 변동함을 확인 했다.

문자를 통해 백신 냉장고 내부의 모니터링 장비가 모니 터링 수신기에 매분 데이터를 전송함을 확인했으며, 데이터 손실 없이 모든 데이터가 들어옴을 확인했다(Fig. 10). 백신 냉장고의 내부/외부 온도, 위치, 고도, 시간, 운송 속도 데이 터를 VCRM 을 활용하여 실시간으로 모니터링 가능 함을 확인했으며, $\mathrm{VCA}$ 를 이용하여 추후 데이터 분석이 가능 함 을 확인했다.

\section{Conclusion}

전 전세계적으로 예방접종 범위의 격차를 개선하고 좁히 고 백신 낭비를 줄이기 위해 백신 운송 작업을 더 잘 관리 할 수 있도록 데이터를 모니터링하는 것이 중요하다. 특히 개발 도상국에서 백신 냉장고 상태를 실시간으로 모니터링 할 수 있다는 것은 예방접종 및 예방접종에 대한 접근성을 확대하는 데 기여할 수 있으며, 이는 많은 전염병을 예방할 뿐만 아니라 국가 차원의 교육 및 경제 개선과 같은 발전 을 가능하게 한다.

본 연구에서는 개발 도상국의 백신 전달을 위한 문자기 반 모니터링 시스템의 적용 가능성을 확인했다. 또한 개발 된 백신 냉장고 와 다양한 운송 방법을 사용하여 현장 테 스트를 수행했다. 제작된 프로토 타입에는 실제로 데이터를 실시간으로 수신할 수 있는지 검토한 결과 문자 통신 방식 을 이용한 데이터 전송은 개발 도상국의 오지 및 농촌에서 도 안정적이라는 결론을 내렸다.

본 연구를 바탕으로, 각 백신 냉장고에 일렬번호를 추가 하여 IoT 네트워크를 생성함으로써 전 지역에서 발생하는 글로벌 백신의 데이터를 동시에 모니터링이 가능 할 것이 다. 이는 백신전달 지역과 전달되지 않은 지역을 파악하여 예방접종 시스템을 더 효율적이고 체계적으로 개선되기를 기대한다.

\section{Acknowledgements}

이 논문은 과학기술정보통신부의 재원으로 한국연구재 단의 지원을 받아 수행된 개도국과학기술지원사업(과제번 호: $2017 \mathrm{~K} 1 \mathrm{~A} 3 \mathrm{~A} 9 \mathrm{~A} 04013801)$ 의 연구 결과입니다.

\section{References}

Aaron, S. W., Fred. W., Eric, N., Boubacar, D., Naawa, S., Danni, D., Emmanuel, A., Alex, G., Mustapha, M., and Tove, K. R. (2017). Vaccine wastage in Nigeria: An assessment of wastage 
rates and related vaccinator knowledge, attitudes and practices.

Ahn, S. H., Lee, K. T., Bhandari, B., Lee, G. Y., Lee, S. Y., and Song, C. K. (2012). Formation Strategy of Renewable Energy Sources for High Mountain Off-grid System Considering Sustainability. Journal of the Korean Society for Precision Engineering, 29(9), pp. 958-963.

Ashok, A., Brison, M., and LeTallec, Y. (2017). Improving cold chain systems: Challenges and solutions, Vaccine, 35, pp. 2217-2223.

Bhandari, B., Lee, K. T., Lee, C. S., Song, C. K., Maskey, R. K., and Ahn, S. H. (2014a). A novel off-grid hybrid power system comprised of solar photovoltaic, wind, and hydro energy sources. Applied Energy, 133, pp. 236-242.

Bhandari, B., Lee, K. T., Lee, G. Y., Cho, Y. M., and Ahn, S. H. (2015). Optimization of hybrid renewable energy power systems: A review. International Journal oF Precision Engineering and Manufacturing-green Technology, 2(1), pp. 99-112.

Bhandari, B., Poudel, S. R., Lee, K. T., and Ahn, S. H. (2014a). Mathematical modeling of hybrid renewable energy system: A review on small hydro-solar-wind power generation. International Journal of Precision Engineering and Manufacturinggreen Technology, 1(2), pp. 157-173.

Byanyuma, M., Yonah, Z. O., Simba, F., and Trojer, L. (2018). Utilization of Broadband Connectivity in Rural and UrbanUnderserved Areas: The case of Selected Areas in ArushaTanzania, International Journal of Computing and Digital Systems, 7, pp.75-83.

Cheriyan, E. (1993). Monitoring the vaccine cold chain, Archives of Disease in Childhood, 69, pp. 600-601.

Hanson, C. M., George, A. M., Sawadogo, A., and Schreiber, B. (2017). Is freezing in the vaccine cold chain an ongoing issue? A literature review, Vaccine, 35, pp. 2127-2133.

Kartoglu, U., and Milstien, J. (2014). Tools and approaches to ensure quality of vaccines throughout the cold chain, Expert Rev. Vaccines, 13(7), pp. 843-854.

Kim, M. S., Bhandari, B., Bhandari, P., Poudel, S. R., Lee, K. T., Chu, W. S., Kim, H. I., Bhattachan, A., Mogasale, V., Lee, S. C., and Ahn, S. H. (2015). Construction of Vaccine Cold-chain at Nepal's Mountainous Regions using Renewable Energy System. Journal of Appropriate Technology, 1(1), pp. 79-83.

Kim, M. S., Mun, J. W., Yu, J. H., Kim, M. S., Bhandari, B., Bak, J., Bhattachan, A., Mogasale, V., Chu, W. S., Lee, S. C., Song, C., and Ahn, S. H. (2020). Impact of renewable energy on extension of vaccine cold-chain: a case study in Nepal, Journal of Appropriate Technology, pp. 94-102.

Kumru, O. S., Joshi, S. B., Smith, D. E., Middaugh, C. R., Prusik, T., and Volkin, D. B. (2014). Vaccine instability in the cold chain: Mechanisms, analysis and formulation strategies, Bio- logicals, 42(5), pp. 237-259.

Lloyd, J., and Cheyne, J. (2017). The origins of the vaccine cold chain and a glimpse of the future, Vaccine, 35, pp. 2115-2120.

Michelle, R. H., and Gregory A. P. (2021). Critical aspects of packaging, storage, preparation, and administration of mRNA and adenovirus-vectored COVID-19 vaccines for optimal efficacy, Vaccine, 39(3), pp. 457-459.

Nelson, C., Froes, P., Van Dyck, A. M., Chavarria, J., Boda, E., Coca, A., Crespo, G., and Lima, H. (2007). Monitoring temperatures in the vaccine cold chain in Bolivia, Vaccine, 25, pp. 433-437.

Setia, S., Mainzer, H., Washington, M. L., Coil, G., Snyder, R., and Weniger, B. G. (2002). Frequency and causes of vaccine wastage, Vaccine, 20, pp. 1148-1156.

Stephane, G., Karen, H., Brent, B., Serguei, D., Christine, N., Selina, Ahmedc, M., and Mahbubur, R. (2010). Vaccine wastage in Bangladesh. Vaccine, 28(3), pp. 858-863.

Wang, X. L., Ha, B. R., Bang, S. M., Yu, J. H., Lee, G. Y., Rhee, H., and Ahn, S. H. (2020a). Low-cost far-field wireless electrical load monitoring system applied in an off -grid rural area of Tanzania, Sustain. Cities Soc, 59, pp. 102209.

Wang, X. L., Rhee, H. S., and Ahn, S. H. (2020b). Off-Grid Power Plant Load Management System Applied in a Rural Area of Africa, Applied Sciences, 10, pp. 4171.

Mun, J. W. (2018). IoT based Vaccine Carrier monitoring and Self-Learning Algorithm to Optimize Power Consumption in Developing Countries, Master's Thesis, Seoul National University, Seoul, South Korea. pp. 10-16.

Park, S. (2019). Portable vaccine carrier and cold chain monitoring system using SMS communication for developing countries. Master's Thesis, Seoul National University, Seoul, South Korea. pp. 18-26.

Energy Information Administration. (2016). International Energy Outlook 2016, with Projections to 2040, DOE/EIA-0484 (2016), U.S. Energy Information Administration, Washington, WA, USA, pp. 81-100

TanzaniaInvest. (2016). TanzaniaInvest, https://www.tanzaniainvest.com/telecoms/vietnamese-telecom-operator-halotelannounces-3g-coverage-of-90-percent-in-tanzania-by-end-of2016 (accessed Aug. 2020).

The Indian Express. (2021). The Indian Express, https://indianexpress.com/article/explained/covid-vaccine-wastage-pm-modicoronavirus-inoculation-drive-7236405/ (accessed Apr. 2020).

WHO. (2020a). WHO, https://apps.who.int/immunization_standards/vaccine_quality/pqs_catalogue/categorypage.aspx?id_cat $=18$ (accessed Apr. 2020).

WHO. (2020b). WHO. https://www.who.int/news-room/factsheets/detail/immunization-coverage(accessed Aug. 2020). 